\title{
Double-blind Parallel Design Pilot Study of Acetyl Levocarnitine in Patients With Alzheimer's Disease
}

\author{
Mary Sano, PhD; Karen Bell, MD; Lucien Cote, MD; George Dooneief, MD; Arlene Lawton, RN; Louise Legler, MA; \\ Karen Marder, MD; Ali Naini, PhD; Yaakov Stern, PhD; Richard Mayeux, MD
}

\begin{abstract}
- Acetyl levocarnitine hydrochloride has been reported to retard dementia in patients with Alzheimer's disease. In a double-blind, parallel design, placebo-controlled pilot study of 30 mild to moderately demented patients with probable Alzheimer's disease, tests of memory, attention, language, visuospatial, and constructional abilities were administered, and the level of acetyl levocarnitine was measured in the cerebrospinal fluid. Patients were then randomly assigned to receive acetyl levocarnitine hydrochloride $(2.5 \mathrm{~g} / \mathrm{d}$ for 3 months followed by $3 \mathrm{~g} / \mathrm{d}$ for 3 months) or placebo. After 6 months, the acetyl levocarnitine group demonstrated significantly less deterioration in timed cancellation tasks and Digit Span (forward) and a trend toward less deterioration in a timed verbal fluency task. No differences were found in any other neuropsychological test results. A subgroup with the lowest baseline scores, receiving acetyl levocarnitine, had significantly less deterioration on the verbal memory test and a significant increase in cerebrospinal fluid acetyl levocarnitine levels compared with those receiving placebo. These results suggest that acetyl levocarnitine may retard the deterioration in some cognitive areas in patients with Alzheimer's disease and stress the need for a larger study of this drug.
\end{abstract}

(Arch Neurol. 1992;49:1137-1141)

A cetyl levocarnitine hydrochloride is structurally similar to acetylcholine and appears to play a role in cerebral glucose utilization and the stimulation of natural scavenger functions to reduce oxidized radicals. It has been reported to improve cognitive function in patients with Alzheimer's disease (AD).$^{1-4}$ Parnetti et al ${ }^{1}$ examined the mental state and behavior in moderately to severely impaired patients with $\mathrm{AD}$ after the intravenous infusion of acetyl levocarnitine hydrocholoride $(15 \mathrm{mg} / \mathrm{kg}$ over 5 minutes $)$ in an open trial without a placebo control group. They found significant improvement over baseline on a mental status examination at 10 and 60 minutes after drug administration. Guarnaschelli et $\mathrm{al}^{2}$ treated a group of elderly patients with cognitive impairment of unclear origin for 6 months with acetyl levocarnitine hydrochloride ( $1.5 \mathrm{~g} / \mathrm{d}$ by mouth) in an open trial. They found a significant improvement over baseline on a mental status examination, a rating of depression, and ratings on a geriatric rating scale at 3 and 6 months. In a group of elderly

\footnotetext{
Accepted for publication May 12, 1992.

From the Departments of Neurology (Drs Sano, Beli, Cote, Dooneief, Marder, Naini, Stern, and Mayeux and Mss Lawton and Legler) and Psychiatry (Drs Stern and Mayeux), Columbia University, College of Physicians and Surgeons; The New York State Psychiatric Institute Memory Disorders Clinic, New York (Drs Sano, Bell, Dooneief, Marder, Stern, and Mayeux); and the Center for Alzheimer's Disease Research (Drs Sano, Marder, Stern, and Mayeux), New York. Dr Sano is a Herbert Irving Assistant Professor in the Department of Neurology.

Reprint requests to the Neurological Institute, $710 \mathrm{~W}$ 168th St, New York, NY 10032 (Dr Sano).
}

patients with mild cognitive impairment, Passeri et $\mathrm{al}^{3}$ found improvement over baseline performance with acetyl levocarnitine hydrochloride ( $2 \mathrm{~g} / \mathrm{d}$ for 3 months) on timed attentional tests, a memory test, and "global performance." Results of comparisons between drug and placebo groups were not statistically significant. Mantero et $\mathrm{al}^{4}$ examined a group of elderly patients with severe cognitive deficits and found significant changes from baseline at the 3- and 6-month follow-up assessments following treatment with acetyl levocarnitine. However, no comparisons with a placebo group were reported.

We examined the effect of acetyl levocarnitine in patients with $\mathrm{AD}$, as diagnosed by established criteria, who had a mild to moderate degree of impairment. A placebocontrolled double-blind parallel design was used.

\section{SUBJECTS AND METHODS Subjects}

Thirty patients between 60 and 80 years of age who met NINCDS-ADRDA ${ }^{5}$ criteria for AD were sequentially enrolled in the study. Patients were recruited from a New York state-funded clinic for dementia. They were living in the community and had mild to moderate impairment, as measured by the Clinical Dementia Rating ${ }^{6}$ of 1 , and were taking no psychoactive medications. All patients provided informed consent and had a regular care giver who was available throughout the study to monitor medication and to provide information about patient status.

\section{Outcome Measures}

Three types of outcome measures were made while investigators were blind to drug or placebo assignment: cognitive tests, functional status, and clinical impression.

A battery of neuropsychological tests was administered to assess cognitive function. This included the Verbal Selective Reminding Test (SRT), ${ }^{7}$ with a 15 -minute delayed recall and delayed recognition components; the modified Mini-Mental State Examination (MMS), ${ }^{8}$ which included Digit Span (forward and backward); the Logical Memory, Paired Associate, and Visual Reproduction subtests from the Wechsler Memory Scale; the Benton Visual Retention Test ${ }^{10}$-Multiple Choice Version (Match and Recognition tests); verbal fluency test for letter ${ }^{11}$; the category naming test ${ }^{12}$; and a cancellation test that scores time and errors. ${ }^{13}$ For the Mini-Mental State Examination (MMS) described by Folstein et $\mathrm{al}^{14}$ the result was estimated from the MMS.

Independent activities of daily living and quality of life were assessed by the care givers using the Sickness Impact Profile $(\mathrm{SIP})^{15}$ and the Squire's Memory Questionnaire (SMQ). ${ }^{16}$

The third outcome measure was the Clinical Global Impression (CGI), completed by a physician who rated the severity of the patient's condition and then determined whether there was a change from baseline. Patients were rated by the same physician at 8-week intervals.

\section{Procedures}

Patients were admitted to the General Clinical Research Center of the Columbia-Presbyterian Medical Center, New York, NY, for baseline assessments. These consisted of a neurologic examina- 
Table 1.-Neuropsychological Test Performance Scores in the Whole Group at Baseline and After 24 Weeks of Drug or Placebo*

\begin{tabular}{|c|c|c|c|c|}
\hline \multirow[b]{2}{*}{ Test } & \multicolumn{2}{|c|}{ Baseline } & \multicolumn{2}{|c|}{24 wk } \\
\hline & Placebo $(n=14)$ & Drug $(n=13)$ & Placebo & Drug \\
\hline $\begin{array}{l}\text { Memory } \\
\text { SRT total recall } \\
\text { Delayed recall } \\
\text { Delayed recognition }\end{array}$ & $\begin{array}{r}21.4(7.6) \\
0.5(1.0) \\
6.4(2.0)\end{array}$ & $\begin{array}{r}22.1(7.3) \\
0.8(0.8) \\
7.1(3.2)\end{array}$ & $\begin{array}{c}16.0(10.0) \\
0.1(0.3) \\
5.2(2.6)\end{array}$ & $\begin{array}{r}21.2(8.8) \\
0.6(1.6) \\
6.5(3.1)\end{array}$ \\
\hline $\begin{array}{l}\text { Wechsler Memory Scale } \\
\text { Logical Memory } \\
\text { Paired Associates } \\
\text { Visual Reproductions }\end{array}$ & $\begin{array}{l}2.9(1.6) \\
6.3(1.4) \\
1.8(1.8)\end{array}$ & $\begin{array}{l}2.8(1.8) \\
7.0(2.0) \\
1.4(1.8)\end{array}$ & $\begin{array}{l}2.2(2.1) \\
6.4(3.9) \\
2.1(2.1)\end{array}$ & $\begin{array}{l}3.0(1.6) \\
6.5(1.9) \\
1.2(1.3)\end{array}$ \\
\hline $\begin{array}{l}\text { Benton Visual Memory Test } \\
\text { Match } \\
\text { Recognition }\end{array}$ & $\begin{array}{l}7.5(2.5) \\
5.8(2.9)\end{array}$ & $\begin{array}{l}7.8(2.6) \\
5.1(2.2)\end{array}$ & $\begin{array}{l}7.1(3.6) \\
5.5(2.3)\end{array}$ & $\begin{array}{l}7.8(3.1) \\
5.3(2.4)\end{array}$ \\
\hline mMMS & $35.3(7.2)$ & $35.5(5.4)$ & $32.4(9.3)$ & $34.3(6.3)$ \\
\hline $\begin{array}{l}\text { Cancellations } \\
\text { Timet } \\
\text { Omission errors }\end{array}$ & $\begin{array}{c}233.8(80.6) \\
4.3(7.7)\end{array}$ & $\begin{array}{c}227.8(73.6) \\
4.2(7.5)\end{array}$ & $\begin{array}{c}299.2(110.3) \\
4.3(5.9)\end{array}$ & $\begin{array}{c}235.0(85.8) \\
3.1(7.5)\end{array}$ \\
\hline $\begin{array}{l}\text { Verbal fluency } \\
\text { Letter } \\
\text { Category }\end{array}$ & $\begin{array}{l}34.5(30.7) \\
23.4(13.0)\end{array}$ & $\begin{array}{l}24.8(33.1) \\
23.8(6.5)\end{array}$ & $\begin{array}{l}26.3(25.9) \\
23.4(13.0)\end{array}$ & $\begin{array}{l}26.8(32.7) \\
23.8(6.5)\end{array}$ \\
\hline $\begin{array}{l}\text { Digit Span } \\
\text { Forward } \\
\text { Backward }\end{array}$ & $\begin{array}{l}5.6(1.1) \\
3.8(1.4)\end{array}$ & $\begin{array}{l}4.9(1.0) \\
3.5(0.7)\end{array}$ & $\begin{array}{l}5.5(1.2) \\
3.6(1.5)\end{array}$ & $\begin{array}{l}5.5(1.3) \\
3.2(0.8)\end{array}$ \\
\hline Sickness Impact Profilet & $27.3(15.6)$ & $25.5(12.5)$ & $24.1(16.5)$ & $22.9(12.5)$ \\
\hline Squires Memory Questionnaire & $38.7(8.5)$ & $38.5(8.3)$ & $45.1(10.8)$ & $45.0(8.8)$ \\
\hline
\end{tabular}

*Values are mean (SD). SRT indicates Selective Reminding Test; mMMS, modified Mini-Mental State Examination.

HHigher scores reflect poorer performance.

\begin{tabular}{|c|c|c|}
\hline Test & $\begin{array}{l}\text { Placebo Group } \\
\qquad(n=14)\end{array}$ & $\begin{array}{l}\text { Drug Group } \\
(n=13)\end{array}$ \\
\hline $\begin{array}{l}\text { Memory } \\
\text { SRT total Recall } \\
\text { Delayed recall } \\
\text { Delayed recognition }\end{array}$ & $\begin{array}{l}-5.3(7.6) \\
-0.4(1.2) \\
-1.1(2.3)\end{array}$ & $\begin{array}{l}-0.8(7.0) \\
-0.4(0.8) \\
-0.1(2.0)\end{array}$ \\
\hline $\begin{array}{l}\text { Wechsler Memory Scale } \\
\text { Logical Memory } \\
\text { Paired Associates } \\
\text { Visual Reproductions }\end{array}$ & $\begin{array}{r}-0.4(2.0) \\
0.9(4.1) \\
0.2(1.7)\end{array}$ & $\begin{array}{r}0.1(1.6) \\
-0.6(1.4) \\
-0.4(1.6)\end{array}$ \\
\hline $\begin{array}{l}\text { Benton Visual Memory Test } \\
\text { Match } \\
\text { Recognition }\end{array}$ & $\begin{array}{l}-0.7(2.2) \\
-1.3(2.1)\end{array}$ & $\begin{array}{l}0.0(1.6) \\
0.3(2.2)\end{array}$ \\
\hline $\mathrm{mMMS}$ & $-2.8(4.3)$ & $-1.3(2.9)$ \\
\hline $\begin{array}{l}\text { Cancellations } \\
\text { Time } \\
\text { Omission errors }\end{array}$ & $\begin{array}{r}-62.1(77.5) \\
-2.7(11.7)\end{array}$ & $\begin{array}{r}4.0(51.9) \dagger \\
-1.7(5.2)\end{array}$ \\
\hline $\begin{array}{l}\text { Verbal fluency } \\
\text { letter } \\
\text { Category }\end{array}$ & $\begin{array}{c}-5.0(16.5) \\
0.2(1.0)\end{array}$ & $\begin{aligned} & 2.0(14.0) \\
- & 0.9(3.6)\end{aligned}$ \\
\hline $\begin{array}{l}\text { Digit Span } \\
\text { Forward } \\
\text { Backward }\end{array}$ & $\begin{array}{l}-0.1(0.9) \\
-0.3(0.7)\end{array}$ & $\begin{array}{r}0.6(1.2) \dagger \\
-0.2(0.7)\end{array}$ \\
\hline Sickness Impact Profile & $3.2(9.8)$ & $5.4(8.1)$ \\
\hline Squires Memory Questionnaire & $6.6(11.7)$ & $6.8(8.3)$ \\
\hline
\end{tabular}

*Values are mean (SD) change from baseline; negative scores reflect poorer performance. SRT indicates Selective Reminding Test; mMMS, modified Mini-Mental State Examination.

tIndicates significant difference by $t$ test and by Wilcoxon Rank-Sum test analysis $(P<.05)$. tion, a lumbar puncture, complete blood cell counts, routine blood chemistry determinations, thyroid function tests, serum vitamin $\mathrm{B}_{12}$ level measurement, a battery of neuropsychological tests, and an assessment of independent function.

Patients were then randomly assigned to receive active drug or placebo (with approximately half assigned to each group). Patients, clinicians, and testers were blind to the drug or placebo status throughout the study. Acetyl levocarnitine hydrochloride was prepared in 500-mg tablets and was administered at a dose of $2500 \mathrm{mg} / \mathrm{d}$ taken in three divided doses with meals (two tablets in the morning, one tablet at midday, and two tablets in the evening) for 12 weeks, followed by an increase to $3000 \mathrm{mg} / \mathrm{d}$ (two tablets in the morning, two tablets at midday, and two tablets in the evening) for an additional 12 weeks. The placebo group received an equal number of apparently identical tablets on the same schedule. Patients were discharged with a supply of medication and returned for outpatient visits at 4-week intervals. At each visit, patients were seen by a physician, were asked about adverse events, and underwent a brief neurologic examination, and a month's supply of study medication was dispensed. Care givers were asked to complete the SIP and SMQ at each visit. The most recent supply of study medications was collected and counted to assess compliance. The CGI was completed by the clinician based on interviews with the patient and family members at 8-week intervals.

Complete blood cell counts and routine blood chemistry determinations were repeated at 4 and 16 weeks. At 24 weeks, patients returned to the General Clinical Research Center and all baseline assessments were repeated. Another lumbar puncture was performed to assess the level of acetyl levocarnitine in the cerebrospinal fluid (CSF).

The level of acetyl levocarnitine in the CSF was quantified according to the method of Pande and Caramancion. ${ }^{17}$ In brief, the acetyl portion of the drug was stoichiometrically converted to citrate in the presence of radiolabeled carbon 14 oxaloacetate, carnitine acetyltransferase, and citrate synthetase. The amount of radioactivity formed was determined. The CSF samples from 
baseline and week 24 were stored at $-70^{\circ} \mathrm{C}$ until the end of the study to protect the blind design.

\section{Data Analysis}

Because this was a pilot study, the analysis was designed to identify group differences on any measure and to examine safety. Therefore, no attempt was made to adjust for multiple comparisons. For each patient, the difference between baseline and 24 weeks was calculated for each cognitive and functional status measure. Mean difference scores were generated for the drug and placebo groups and comparisons were made with the use of a $t$ test. The CGI ratings for the drug and placebo groups were also compared with the use of a $t$ test at each 8-week interval. In addition, the Wilcoxon Rank-Sum test was used to compare the drug and placebo groups on each measure. Difference scores were categorized as stable $(\geq 0)$ or deteriorated $(<0)$, and drug vs placebo group comparisons were examined with the use of $x^{2}$ tests.

In a post hoc analysis, patients were divided into two subgroups of equal size, according to baseline mMMS scores. Drug vs placebo group comparisons were made within subgroups with high and low mMMS scores. To examine the association between CSF acetyl levocarnitine level and behavioral improvements, patients in the drug group were also subdivided according to the difference in CSF acetyl levocarnitine level between baseline and 24 weeks, and comparisons between these subgroups for cognitive measures were made with the use of $t$ tests.

\section{RESULTS}

Three patients did not complete the trial. One became agitated, required antipsychotic medication, and withdrew from the study. Another patient died of a cause unrelated to the study medication. The third patient broke the blind design of the study by having the study medication analyzed. Data for the remaining 27 patients were analyzed. Compliance with the medication regimen was monitored and was found to be greater than $80 \%$ in all subjects who completed the 6-month trial.

The drug and placebo groups were matched on demographic variables and were equivalent on all measures at baseline. The means (SDs) for the drug and placebo groups, respectively, were as follows: age, $67.6(6.0)$ and $71.2(6.8)$ years; education, 14.2 (3.4) and 15.2 (3.5) years; duration of illness, 3.6 (1.3) and 3.0 (1.4) years; and estimated baseline MMS score, 18.4 (4.0) and 19.1 (3.2).

Table 1 presents the baseline and 24-week performance for the two groups on each neuropsychological test. There was no significant difference between the two groups on any measure at baseline. Tables 2 and 3 list the change from baseline and the percentage of patients demonstrating stable or improved performance on neuropsychological tests and measures of independent function. There was a significant improvement in the drug group compared with the placebo group on the cancellation task and Digit Span (forward). Borderline significance was demonstrated in the verbal fluency test $(P=.052)$ and the Logical Memory subtest of the Wechsler Memory Scale $(P=.052)$. There was a significant difference $(P<.05)$ on the CGI at 8 weeks, but not at 16 or 24 weeks. There was no significant difference in either the SIP or the SMQ. The CSF levels of acetyl levocarnitine are shown in Table 4 . There was no difference between the drug and placebo groups in the CSF concentration of acetyl levocarnitine.

\section{Results of Subgroup Analysis}

In the subgroup with low baseline mMMS scores, less deterioration was noted on the SRT in the drug group compared with the placebo group $(P<.05)$. Table 5 de-

\begin{tabular}{|c|c|c|}
\hline $\begin{array}{l}\text { Table } 3 . \text { Percent of Patien } \\
\text { Improved Performance on } \\
\text { After } 24\end{array}$ & $\begin{array}{l}\text { ts Demonstrati } \\
\text { Neuropsycholo } \\
\text { Weeks* }\end{array}$ & $\begin{array}{l}\text { ng Stable or } \\
\text { gical Tests }\end{array}$ \\
\hline \multirow[b]{2}{*}{ Test } & \multicolumn{2}{|c|}{$\%$ Stable or Improved } \\
\hline & $\begin{array}{l}\text { Placebo Group } \\
\qquad(n=14)\end{array}$ & $\begin{array}{l}\text { Drug Group } \\
(n=13)\end{array}$ \\
\hline $\begin{array}{l}\text { Memory } \\
\text { SRT total recall } \\
\text { Delayed recall } \\
\text { Delayed recognition }\end{array}$ & $\begin{array}{l}21.4 \\
75.0 \\
28.6\end{array}$ & $\begin{array}{l}38.5 \\
81.8 \\
63.6\end{array}$ \\
\hline $\begin{array}{l}\text { Wechsler Memory Scale } \\
\text { Logical Memory } \\
\text { Paired Associates } \\
\text { Visual Reproductions }\end{array}$ & $\begin{array}{l}38.5 \\
54.5 \\
72.7\end{array}$ & $\begin{array}{l}66.7 \\
58.3 \\
54.5\end{array}$ \\
\hline $\begin{array}{l}\text { Benton Visual Retention Test } \\
\text { Match } \\
\text { Recognition }\end{array}$ & $\begin{array}{l}54.5 \\
50.0\end{array}$ & $\begin{array}{l}76.9 \\
66.7\end{array}$ \\
\hline mMMS & 21.4 & 53.9 \\
\hline $\begin{array}{l}\text { Cancellations } \\
\text { Time } \\
\text { Omission errors }\end{array}$ & $\begin{array}{l}41.7 \\
61.5\end{array}$ & $\begin{array}{c}100.0 t \\
54.5\end{array}$ \\
\hline $\begin{array}{l}\text { Verbal fluency } \\
\text { Letter } \\
\text { Category }\end{array}$ & $\begin{array}{l}30.8 \\
76.9\end{array}$ & $\begin{array}{l}69.2+ \\
76.9\end{array}$ \\
\hline $\begin{array}{l}\text { Digit Span } \\
\text { Forward } \\
\text { Backward }\end{array}$ & $\begin{array}{l}57.1 \\
57.1\end{array}$ & $\begin{array}{l}92.3 t \\
61.5\end{array}$ \\
\hline Sickness Impact Profile & 64.3 & 72.7 \\
\hline Squires Memory Questionnaire & 64.3 & 83.3 \\
\hline
\end{tabular}

*SRT indicates Selective Reminding Test; mMMS, modified MiniMental State Examination.

tIndicates significant difference by $\chi^{2}$ analysis $(P<.05)$.

\begin{tabular}{|c|c|c|c|c|}
\hline \multirow{3}{*}{$\begin{array}{l}\text { Drug }(n=11) \\
\text { Placebo }(n=14)\end{array}$} & \multirow{3}{*}{ 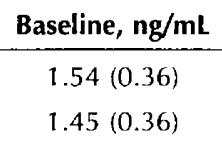 } & \multirow{3}{*}{ 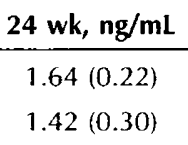 } & \multicolumn{2}{|c|}{ Difference, $\mathrm{ng} / \mathrm{mL}+$} \\
\hline & & & $0.163(0.30)$ & $(t-1, A \cdot N C$ \\
\hline & & & $-0.029(0.35)$ & $(l=1.4 ; N S)$ \\
\hline $\begin{array}{l}\text { Patients with } m N \\
\text { Drug }(n=6) \\
\text { Placebo }(n=6)\end{array}$ & $\begin{array}{l}1.41(0.16) \\
1.62(0.30)\end{array}$ & $\begin{array}{l}1.78(0.16) \\
1.49(0.24)\end{array}$ & $\left.\begin{array}{r}0.312(0.22) \\
-0.125(0.32)\end{array}\right]$ & $(t=2.0 ; P<.05)$ \\
\hline $\begin{array}{l}\text { Patients with } \mathrm{mM} \\
\text { Drug }(\mathrm{n}=5) \\
\text { Placebo }(\mathrm{n}=8)\end{array}$ & $\begin{array}{l}1.64(0.30) \\
1.32(0.30)\end{array}$ & $\begin{array}{l}1.55(0.25) \\
1.36(0.34)\end{array}$ & $\left.\begin{array}{r}-0.014(0.29) \\
0.042(0.38)\end{array}\right]$ & $(t=1.7 ; \mathrm{NS})$ \\
\hline
\end{tabular}

*Values are mean (SD). mMMS indicates modified Mini-Mental State Examination, NS, not significant.

+Negative values indicate a decrease in acetyl levocarnitine level. 


\begin{tabular}{|c|c|c|c|c|}
\hline \multirow[b]{2}{*}{ Test } & \multicolumn{2}{|c|}{ Baseline } & \multicolumn{2}{|c|}{24 wk } \\
\hline & $\begin{array}{l}\text { Placebo } \\
(n-6)\end{array}$ & $\begin{array}{l}\text { Drug } \\
(n=6)\end{array}$ & Placebo & Drug \\
\hline $\begin{array}{l}\text { Memory } \\
\text { SRT total recall } \\
\text { Delayed recall } \\
\text { Delayed recognition }\end{array}$ & $\begin{array}{r}18.3(7.2) \\
0.2(0.4) \\
5.8(2.0)\end{array}$ & $\begin{array}{r}20.8(7.8) \\
0.0(0.0) \\
5.5(2.5)\end{array}$ & $\begin{array}{l}8.0(3.7) \\
0.0(0.0) \\
5.0(3.6)\end{array}$ & $\begin{array}{r}20.1(7.1) \\
0.0(0.0) \\
5.3(2.5)\end{array}$ \\
\hline $\begin{array}{l}\text { Wechsler Memory Scale } \\
\text { Logical Memory } \\
\text { Paired Associates } \\
\text { Visual Reproductions }\end{array}$ & $\begin{array}{l}2.4(1.8) \\
5.0(1.1) \\
1.3(2.5)\end{array}$ & $\begin{array}{l}2.8(2.0) \\
6.2(2.1) \\
0.7(0.8)\end{array}$ & $\begin{array}{l}1.1(1.0) \\
3.7(4.8) \\
1.3(2.3)\end{array}$ & $\begin{array}{l}2.4(1.9) \\
5.8(2.0) \\
0.8(1.2)\end{array}$ \\
\hline $\begin{array}{l}\text { Benton Visual Memory Te } \\
\text { Match } \\
\text { Recognition }\end{array}$ & $\begin{array}{l}6.8(2.6) \\
4.0(3.7)\end{array}$ & $\begin{array}{l}7.5(3.0) \\
4.2(1.1)\end{array}$ & $\begin{array}{l}5.5(3.6) \\
5.5(2.3)\end{array}$ & $\begin{array}{l}7.8(3.1) \\
5.3(2.4)\end{array}$ \\
\hline mMMS & $28.7(3.6)$ & $31.3(3.9)$ & $24.5(5.0)$ & $30.0(3.5)$ \\
\hline $\begin{array}{l}\text { Cancellations } \\
\text { Timet } \\
\text { Omission errors }\end{array}$ & $\begin{array}{c}236.0(103.3) \\
5.2(3.2)\end{array}$ & $\begin{array}{c}236.0(58.6) \\
7.2(3.8)\end{array}$ & $\begin{array}{c}334.6(91.2) \\
8.4(9.3)\end{array}$ & $\begin{array}{c}224.8(88.3) \\
11.0(5.4)\end{array}$ \\
\hline $\begin{array}{l}\text { Verbal fluency } \\
\text { Letter } \\
\text { Category }\end{array}$ & $\begin{array}{l}22.7(11.1) \\
13.8(4.2)\end{array}$ & $\begin{array}{l}20.0(12.7) \\
22.2(8.6)\end{array}$ & $\begin{array}{l}19.3(11.7) \\
11.7(7.1)\end{array}$ & $\begin{array}{l}23.0(14.0) \\
19.7(8.7)\end{array}$ \\
\hline $\begin{array}{l}\text { Digit Span } \\
\text { Forward } \\
\text { Backward }\end{array}$ & $\begin{array}{l}4.8(0.8) \\
3.2(1.0)\end{array}$ & $\begin{array}{l}4.6(0.8) \\
3.2(0.4)\end{array}$ & $\begin{array}{l}4.7(0.5) \\
3.0(1.5)\end{array}$ & $\begin{array}{l}5.5(1.2) \\
3.0(0.6)\end{array}$ \\
\hline Sickness Impact Profilet & $40.5(14.0)$ & $33.0(5.1)$ & $40.3(10.0)$ & $28.2(11.2)$ \\
\hline $\begin{array}{l}\text { Squires Memory } \\
\text { Questionnaire }\end{array}$ & $33.5(5.6)$ & $38.5(10.3)$ & $39.5(11.0)$ & $44.0(8.0)$ \\
\hline
\end{tabular}

*Values are mean (SD). SRT indicates Selective Reminding Test; mMMS, modified Mini-Mental State Examination.

HHigher scores reflect poorer performance.

scribes the baseline and 24-week performance for the two groups on each neuropsychological test. There was no significant difference at baseline on any test. The mean change in the SRT scores among those receiving drug was $1.4 \%$ increase, while the placebo group demonstrated a mean drop of $54 \%$ in memory test scores. This subgroup also demonstrated improvement in verbal fluency, cancellations, and Digit Span (forward). Among those patients with low mMMS scores, there was also a significant increase in the CSF acetyl levocarnitine level at 24 weeks $(P<.05)$ in the drug group compared with the placebo group. There was no significant difference in neuropsychological test scores, CGI ratings, or CSF drug levels between the drug and placebo groups among the patients with high mMMS scores.

An additonal analysis compared subgroups of patients with high and low CSF changes. There was a trend toward improvement $(P=.059)$ in the group with a high CSF drug level compared with the group with a low CSF drug level with regard to the time to complete the cancellation task.

\section{Summary of Adverse Events}

There were no changes in clinical hematologic or blood chemistry results, and few adverse events were reported. Four patients experienced adverse events that were deemed "possibly related to study medication." Three patients were in the placebo group, two of whom experienced nausea and vomiting and one of whom experienced abdominal discomfort. One patient in the drug group experienced nonspecific abdominal discomfort.

\section{COMMENT}

Our results could be interpreted to suggest that acetyl levocarnitine may retard the deterioration of performance on some tasks in patients with AD. The specific tasks demonstrating a benefit were Digit Span (forward), timed tasks of attention, and verbal fluency. Passeri et $\mathrm{al}^{3}$ also reported improvement in verbal fluency and in the completion time of a target detection task.

Previous investigations involving acetyl levocarnitine found no significant differences between drug and placebo and suggested that the treatment period may need to be as long as 6 months. In contrast, we found improvement in the CGI rating only at 8 weeks, with no benefit evident at 12 or 24 weeks.

We did not find a benefit in memory testing in the overall analysis. This may be due to the small sample size involved in this pilot study. Results of the SRT were examined to estimate the power of our study to detect a benefit in memory with the use of methods described by Cohen. ${ }^{18}$ The effect size from group mean and proportional comparisons ranged from 0.4 to 0.6 . The group size in our study yields power in the range of $18 \%$ to $33 \%$ for an $\alpha$ value of .05 (two-tailed). Based on the effect size in our study, a much larger sample size ( 30 to 45 per group) would be required to achieve power of $80 \%$.

The subgroup analysis suggested that memory, attention, and verbal fluency appear to be most improved in patients with moderate, rather than mild, impairment. These patients also demonstrated a significant increase in the CSF acetyl levocarnitine levels. In addition, post hoc 
analysis suggested a relationship between CSF acetyl levocholine levels and improvement on a timed task. This relationship between central measures of the drug and a behavioral response to our knowledge has not been noted before, perhaps because previous studies used lower doses $^{2-4}$ than were used in our study.

Several reports have suggested an improvement in quality of life, ${ }^{2,4}$ although this was not systematically measured. We found no evidence of an improvement in quality of life, as indicated by the absence of change on the SIP or SMQ.

The mechanism of action of acetyl levocarnitine is unknown, but several possible mechanisms have been postulated. It has been reported to activate choline acetyltransferase, increase high-affinity uptake, and have a specific cholinomimetic effect. ${ }^{19}$ In addition, in rodent studies it has been found to increase gamma-aminobutyric acid in the substantia nigra. ${ }^{20}$ This is of particular interest given our findings of benefits on timed tasks. Because disruption of this system is associated with cognitive and motor slowing, further studies might focus on patients with AD with extrapyramidal involvement.

There have been no direct comparisons between acetyl levocarnitine and other agents in the treatment of $\mathrm{AD}$. Clinical trials of tetrahydroaminoacridine $e^{21,22}$ have yielded mixed results, with the most recent studies suggesting no benefit over placebo and substantial systemic side effects and laboratory abnormalities. Our study, along with previous reports, ${ }^{1-4}$ suggests that acetyl levocarnitine is relatively safe, with no adverse systemic side effects and no changes in liver enzyme or serum electrolyte levels.

Cholinergic agonists are relatively ineffective in improving memory in patients with $\mathrm{AD}^{23}$ Clinical trials with cholinesterase inhibitors have yielded unclear results. Some studies with oral physostigmine salicylate report no bene$\mathrm{fit}^{24,25}$ and others demonstrate small, but statistically significant, improvement in memory in patients with $\mathrm{AD}_{1}^{26,27}$ particularly when the drug is administered for relatively long periods. ${ }^{27}$ We found a benefit on cognitive tests, but improvement in memory was seen in only a subset of patients.

Our study was a pilot study designed to identify possible directions for further evaluation of this drug under the rigorous structure of a double-blind protocol. For this reason, we used many outcome variables to spread the widest possible net to capture any domain of change. Because our objective was to describe patterns of change to plan further investigations, and not to make decisions about the efficacy of this drug, we have presented our results unadjusted for multiple comparisons, as recommended by Rothman..$^{28}$

Overall, our study demonstrated mild improvement in attention and timed tasks in patients with AD. Benefits in memory were only seen in more impaired patients who also showed an increase in CSF acetyl levocarnitine concentrations. The relatively long exposure (ie, 6 months) to this drug was an attempt to examine the effect on disease progression. However, it is unknown whether the specific outcome variables used herein were sensitive to progression of AD. Future efforts should be targeted to patients with moderate impairment and perhaps should employ longer intervals of drug exposure.

This investigation was supported by federal grants AG-08702 from the National Institute of Aging and RR00645 from the National Institutes of Health, Bethesda, Md, to the Clinical Research Center, Pres- byterian Hospital, New York, NY, and The Charles S. Robertson Memorial Gift for Research in Alzheimer's Disease. Sigma Tau Pharmaceutical Co, Pomezia, Rome, Italy, also provided financial support and supplied drug and placebo.

The authors gratefully acknowledge the contributions of Drs Ming Xin Tang and Danielle Rebischung and James Wilson.

\section{References}

1. Parnetti L, Gaiti A, Meococci $P$, et al. Effect of acetyl-I-carnitine on serum levels of cortisol and adrenocorticotropic hormone and its clinical effect in patients with senile dementia of Aizheimer's type. Dementia. 1990;1:165-168.

2. Guarnaschelli C, Fugazza G, Pistarini C. Pathological brain aging: evaluation of efficacy of a pharmacological aid. Drugs Exp Clin Res. 1988; 14:715-718.

3. Passeri $M$, lannuccelli $M$, Ciotti $G$, Bonati $P$, Nolfe $G$, Cucinotta D. Mental impairment in aging: selection of patients, methods of evaluation and therapeutic possibilities of acetyl-I-carnitine. Int J Clin Pharmacol Res. 1988; $8: 367-376$.

4. Mantero MA, Barero M, Giannini R, Grosso VG, Tomasina C, lannuccelli $M$. Acetyl-I-carnitine as a therapeutic agent for mental deterioration in geriatric patients (double-blind controlled versus placebo study). Clin Neuropharmacol. 1989;3:17-24.

5. McKhann G, Drachman D, Folstein M, Katzman R, Price D, Stadlan EM. Clinical diagnosis of Alzheimer's disease: Report of the NINCDS-ADRDA work group: under the auspices of the Dept of Health and Human Services Task Force on Alzheimer's Disease. Neurology. 1984;34:939-944.

6. Burke WJ, Miller JP, Rubin EH, et al. The reliability of the Washington University Clinical Dementia Rating. Arch Neurol. 1988;45:31-32.

7. Buschke $H$, Fuld PA. Evaluating storage, retention and retrieval in disordered memory and learning. Neurology. 1974;24:1019-1025.

8. Stern Y, Sano M, Paulson J, Mayeux R. Modified Mini-Mental State Examination: validity and reliability. Neurology. 1987;37(suppl 1):179.

9. Wechsler D. A standarized memory scale for clinical use. J Psychol. 1945; 19:87-95

10. Benton AL. The Visual Retention Test. New York, NY: The Psychologjcal Corp; 1955

11. Benton A. FAS test. In: Spreen O, Benton A, eds. Neurosensory Center Comprehensive Examination for Aphasia. Victoria, British Columbia: University of Victoria; 1967.

12. Goodglass H, Kaplan E. The Assessment of Aphasia and Related Disorders. 2nd ed. Philadelphia, Pa: Lea \& Febiger; 1983.

13. Sano M, Rosen W, Mayeux R. Attention deficits in Alzheimer's disease. Presented at the 92nd Annual Meeting of the American Psychological Association; August 19, 1984; Toronto, Ontario.

14. Folstein MF, Folstein SE, McHugh PR. 'Mini-Mental State': a practical method for grading the cognitive state of patients for the clinician. J Psychiatr Res. 1975;12:189-198.

15. Bergner M, Bobbitt R, Carter W, Gilson B. The Sickness Impact Profile: development and final revision of a health status measure. Med Care. 1981;19:787-805.

16. Squire LR, Wetzel CD, Slater PC. Memory complaint after ECT: assessment with a new self-rating instrument. Biol Psychiatry. 1979;14:791-801.

17. Pande SV, Caramancion NM. A simple radioisotopic assay of acetylcarnitine and acetyl-CoA at picomolar levels. Anal Biochem. 1981;112;30-38.

18. Cohen J. Statistical Power Analysis for the Behavioral Sciences. Orlando, Fla: Academic Press Inc; 1977.

19. Clinical Investigators Brochure: Acetyl-L-carnitine Hydrochloride. Gaithersburg, Md: Sigma Tau Pharmaceuticals Inc; 1990.

20. Fariello RG, Ferraro TN, Golden GT, DeMattei M. Systemic acetyl-Lcarnitine elevates nigral levels of glutathione and GABA. Life Sci. 1988;43: 289-292.

21. Summers WK, Majovski LV, Marsch GM, Tachiki K, Kling A. Oral tetrahydroaminoacridine in long-term treatment of senile dementia: Alzheimer's disease. N Engl J Med. 1986;315:1241-1245.

22. Gauthier $S$, Bouchard $R$, Lamontagne $A$, et al. Tetrahydroaminoacridine-lecithin combination treatment in patients with intermediatestage Alzheimer's disease. N Eng/ J Med. 1990;322:1272-1276.

23. Penn RD, Martin EM Wilson RS, Fox JH, Savoy SM. Intraventricular bethanechol infusion for Alzheimer's disease: results of double-blind and escalating-dose trials. Neurology. 1988;38:219-222.

24. Stern $Y$, Sano $M$, Mayeux R. Effects of oral physostigmine in Alzheimer's disease. Ann Neurol. 3987;22:306-310.

25. Beller SA, Overall JE, Swann AC. Efficacy of oral physostigmine in primary degenerative dementia. Psychopharmacology. 1985;87:147-151.

26. Mohs RC, Davis BM, Johns CA, et al. Oral physostogmine treatment of patients with Alzheimer's disease. Am / Psychiatry. 1985;142:28-33.

27. Stern Y, Sano M, Mayeux R. Long-term administration of oral physostigmine in Alzheimer's disease. Neurology. 1988;38:1837-1841.

28. Rothman KJ. No adjustment is needed for multiple comparisons. Epidemiology. 1990;1:43-46. 